\title{
$\angle S$ Research Square \\ Effect of tetrandrine combined with arsenic trioxide on stem cells of triple negative breast cancer
}

\section{Yubo Guo}

The third affiliated hospital of Beijing university of Chinese Medicine https://orcid.org/0000-0002-

9724-1649

\section{Yingyi Fan}

The third affiliated hospital of Beijing University of Chinese Medicine

\section{Ruixian Wu}

Sanya city womenfolk infant health care hospital

Xiaohua Pei (D pxh_127@163.com )

\section{Research article}

Keywords: Tetrandrine; arsenic trioxide; MDA-MB-231 cell; stem cells

Posted Date: June 10th, 2019

DOI: https://doi.org/10.21203/rs.2.10175/v1

License: (c) (i) This work is licensed under a Creative Commons Attribution 4.0 International License.

Read Full License 


\section{Abstract}

Background Although the triple negative breast cancer is sensitive to chemotherapy, breast cancer stem cells (BCSCs) is the origin of tumor chemotherapy resistance, tumor recurrence and tumor invasion and metastasis. This study aims to examine the effect of tetrandrine combine with arsenic trioxide on BCSCs and potential mechanism of anti- triple negative breast cancer metastasis. Methods We cultured the triple negative breast cancer cell MDA-MB-231 and induced BCSCs sphere formation by serum-free medium for 5 days. In the MDA-MB-231 cell and MDA-MB-231 stem cell, we compared the ratio of CD44+/CD24- and sorted stem cells by flow cytometry, the expression of Oct 4 and Sox 2 mRNA were by rt-PCR, invasion ability were by Transwell assay. We subsequently measured the effect of tetrandrine combine with arsenic trioxide on BCSCs proliferation by CCK8 method. The stem cell morphology observation was by trypan blue staining. Stem cell cycle and apoptosis were evaluated by flow cytometry. Western Blot was used to measure the protein levels of Hedgehog, Notch1 and PTEN signaling of BCSCs. Results The ratio of CD44+/CD24- in MDA-MB-231 stem cells was $95.0 \%$, while MDA-MB-231 cell was $89.3 \%$. The invasion number of MDA-MB-231 stem cell was significantly higher than that of MDA-MB-231 cells $(p<0.01)$. Furthermore, we demonstrated that tetrandrine and arsenic trioxide could inhibit the BCSCs proliferation. Tetrandrine combine with arsenic trioxide could significantly promote the apoptosis $(p<0.01)$ and increase the percentage of G0/G1 phase and decrease the G2/M phase $(p<0.01)$ of BCSCs. Compared with the control group, arsenic trioxide, tetrandrine and the combined group could significantly reduce the expression of GLI1 and SMO and increase the expression of PTEN protein $(\mathrm{P}<0.05)$. Conclusions These findings revealed that tetrandrine combined with arsenic trioxide could suppress the proliferation and induce apoptosis of BCSCs by decreased Gli and SMO expression and increased PTEN expression. Targeting BCSCs treatment, this study provides potential therapeutic drugs against triple negative breast cancer metastasis.

\section{Background}

With the using of conventional therapeutic surgery, radiotherapy, chemotherapy, hormones and color Doppler ultrasound, mammography, MRI imaging, breast cancer achieved early diagnosis and early treatment, and improved the 5-year survival rate of breast cancer patients. However, breast cancer is still the second leading cause of cancer death in women, which is due to the tumor recurrence and metastasis ${ }^{[1]}$. Breast cancer is divided into luminal A, luminal $B, H E R 2$, and triple negative breast cancer (TNBC). Among them, TNBC is the most invasive subtype with high metastatic potential. It may be due to a large number of breast cancer stem cell (BCSC) populations present in TNBC tumors ${ }^{[2]}$. Breast cancer stem cells (BCSCs) are derived from human breast tumors and mainly with the ability to regenerate breast malignant cells and force the growth of the breast cancer. BCSCs are with the characteristics of resistance to radiotherapy and chemotherapy, hypoxia tolerance, high tumorigenicity, high invasion and metastasis, contributing to tumor recurrence and metastasis. Traditional treatments only kill most differentiated tumor cells, and a few remaining cancer stem cells are the source of tumor recurrence and metastasis ${ }^{[3]}$. BCSCs has established with a minimum cell surface markers $\mathrm{CD}_{4} 4^{+} / \mathrm{CD} 24^{-}$and 
$\mathrm{CD}_{4} 4^{+} / \mathrm{CD} 24^{-}$phenotype cell population enhancement showing increased tumorigenicity and invasion ${ }^{[4]}$. It's found that a large number of $\mathrm{CD} 44^{+} / \mathrm{CD} 24^{-}$and ALDH-positive cells and microsphere formation were observed in basal-like breast cancer cells, and is more resistant to chemotherapy, hormone therapy, and radiation therapy, indicating that triple-negative breast cancer cells have a higher incidence of cancer than other subtypes ${ }^{[5,6]}$.

Arsenic trioxide $\left(\mathrm{As}_{2} \mathrm{O}_{3}, \mathrm{ATO}\right)$ is an effective active ingredient of arsenic. In modern research, arsenic trioxide has widely applied to treat acute promyelocytic leukemia ${ }^{[7]}$, for other malignant tumors such as lung cancer ${ }^{[8]}$, colon cancer ${ }^{[9]}$, liver cancer ${ }^{[10]}$, gastric cancer ${ }^{[11]}$, pancreatic cancer ${ }^{[12]}$, ovarian cancer ${ }^{[13]}$ and breast cancer ${ }^{[14]}$. ATO, in vitro, could induce human breast cancer MCF-7 cells to arrest in $\mathrm{G} 1$ phase and induce MDA-MB-231 and MDA-MB-468 cells to arrest in G2/M phase ${ }^{[15]}$. Besides, ATO could inhibit tumor growth in vivo after inoculation of MCF-7 cells into nude mice, induce apoptosis and inhibit growth in MCF-7 breast cancer cells in vitro ${ }^{[16]}$. Elevation of the cancer stem cells (CSCs) like properties is associated with the onset of human cancer, tumorigenesis, metastasis and recurrence, through the stem cell processes of self-renewal and differentiation into multiple cell types. ATO attenuated the CSCs-like properties in human hepatocellular carcinoma ${ }^{[17]}$. Tetrandrine (Tet), a bisbenzylisoquinoline alkaloid extracted from Stephania tetrandra SIMoore, has been reported to treat patients with tumors, such as prostate cancer ${ }^{[18]}$, lung cancer ${ }^{[19]}$, breast cancer ${ }^{[20]}$. Our group had demonstrated the apparent cytotoxic effect of $\mathrm{A}_{\mathrm{S} 2} \mathrm{O}_{3}$ on ER-positive human breast cancer MCF-7 cell, and further elucidated that tetrandrine synergized with arsenic trioxide to significantly enhance toxicity to ER-positive human breast cancer cells $^{[21]}$. However, whether ATO and Tet could inhibit the human triple negative breast cancer MDA-MB231 cell and the associated mechanism is unclear.

Notch signaling, Hedgehog signaling cascade and PTEN, the important CSC signaling pathways, have been related to the regulating proliferation, self-renewal, differentiation, maintenance of CSCs ${ }^{\text {[22] }}$. However, whether ATO combined with Tet could decrease the metastatic characteristics of BCSCs and the mechanism is not clear. Stem cell invasion and metastasis is strong, so we take BCSCs as research objects. We hypothesized that stem cells can be isolated from breast cancer cells. The combination of arsenic trioxide and tetrandrine could inhibit stem cell proliferation and induce apoptosis, thereby inhibiting stem cell metastasis. Furthermore, we aim to investigate whether the inhibition is related to the Hedgehog, Notch, and PTEN signaling pathways to explore the anti-breast cancer metastasis mechanisms of tetrandrine combine with arsenic trioxide targeting BCSCs.

In this study, serum-free enrichment of breast cancer stem cells was carried out by adding growth factors to the culture medium. In order to identify the characteristics of the isolated mammary stem cells, the ratio of $\mathrm{CD} 44^{+} / \mathrm{CD} 24-$ in stem cells was detected by flow cytometry, and the expression of Sox 2 and Oct4 mRNA of stem cells were detected by QPCR, invasive of breast cancer stem cells with transwell assay. Furthermore, we measured the effect of tetrandrine and arsenic trioxide on the morphology, proliferation, cell apoptosis and cycle of breast cancer stem cell. In addition, we investigate its potential association with the Hedgehog signaling, PTEN and Notch pathways. This study is expected to provide a preliminary 
basis for the study of anti-metastasis of arsenic trioxide combined with tetrandrine against breast cancer stem cells and experimental evidence for arsenic trioxide combined with tetrandrine clinically anti-breast cancer metastasis.

\section{Methods}

\section{- Chemicals and Reagents.}

B27 (Life Technologies,USA,NY14072), DMEM/F12 (Gibco,USA,AC10238685), bFGF (novoprotein,Shanghai,China,C046), EGF(novoprotein,Shanghai,C029), 0.4\% Trypan blue dye solution (Solarbio,Beijing,China,Cat\#C0040), CD44-PE(BD,USA,550989), CD24-FITC(BD,USA,555427), PE (BD,USA,555749), FITC(BD,USA,553456), Agarose (ABI-invitrogen,USA,16500100), TRIZOL(Invitrogen,USA,10296028), SuperScript III RT Reverse Transcription Kit (ABIinvitrogen,USA,11752050), Sybr QPCR mix (ABI-invitrogen,USA,4472920), DAPI (Solarbio, Beijing,China,C0065), Matrigel Matrix Basement Membrane(Corning,USA,356234), CCK8(Dojindo,Japan,LB633), Matrigel Matrix Basement Membrane (Corning,USA,356234). All other reagents were obtained from Sigma-Adrich Co. (St. Louis, MO, USA). The epidermal growth factor (EGF) was prepared into a mother liquor at a concentration of $100 \mu \mathrm{g} / \mathrm{mL}$, and basic fibroblast growth factor (bFGF) was prepared to prepare a mother liquor having a concentration of $100 \mu \mathrm{g} / \mathrm{mL}$, and stored at $-20^{\circ} \mathrm{C}$. The stem cell medium was serum-free medium DMEM/F12, supplemented with bFGF (10ng/mL), EGF $(20 \mathrm{ng} / \mathrm{mL})$ and $2 \% \mathrm{~B} 27$, stored at $4^{\circ} \mathrm{C}$ and protected from light.

Tetrandrine standard was purchased from China Food and Drug Administration Institute, cat. No. 110711201609. Tetrandrine solution was added DMSO to help dissolve and the final concentration of DMSO is less than $0.1 \%$. The Tetrandrine mother solution was mixed with the DMEM culture to a final concentration of $36 \mu \mathrm{g} / \mathrm{mL}$, filtered through a $0.22 \mu \mathrm{m}$ filter, stored at $-20^{\circ} \mathrm{C}$ and protected from light. Arsenic acid injection was purchased from Heilongjiang Harbin Medical University Pharmaceutical Co., Ltd. Cat. No. H19990191. Arsenic trioxide mother solution was mixed with DMEM culture solution to a final concentration of $100 \mu \mathrm{g} / \mathrm{mL}$, stored at $-20^{\circ} \mathrm{C}$ and protected from light.

\section{- Breast cancer stem cell culture}

The MDA-MB-231 single cells were plated at a density of $1 \times 10^{4}$ cells in serum-free medium DMEM/F12, supplemented with commercial hormone mix $2 \% B 27$, EGF $(20 \mathrm{ng} / \mathrm{mL})$, bFGF $(10 \mathrm{ng} / \mathrm{mL})$ and inoculated into a low-adsorption 6-well plate cultured for 5 days when cells started to grow forming floating aggregates. Then, the MDA-MB-231 stem cells were resuspended in DMEM medium supplemented with $10 \%$ fetal bovine cultured in a $37^{\circ} \mathrm{C}, 5 \% \mathrm{CO}^{2}$ incubator. Cells were counted after $0.4 \%$ trypan blue staining and the growth curve was drawn by averaging. The cell growth curve was plotted with time as the horizontal axis and cell number as the vertical axis.

\section{- Flowcytometric analysis of CD44 and CD24 content}


Logarithmic growth phase MDA-MB-231 cells and 5 days of stem cells were suspended in DMEM complete medium and DMEM/F12 serum-free medium to prepare single cell suspension. The number of cells was adjusted to $1 \times 10^{6} \mathrm{cells} / \mathrm{ml}$. The cells were washed with PBS. Then, the cells were resuspended in $100 \mu \mathrm{l}$ of PBS, and labeled with CD44-PE and CD24-FITC, respectively. Each fluorescent antibody was set up with an isotype control. Incubate the cells in the dark for $15 \mathrm{~min}$ at room temperature, centrifuge at I000rpm for 5 min and then test with $200 \mu$ I PBS on the flow cytometry to detect the expression of CD44 and CD24.

\section{- Assay for the detection of apoptosis and cell cycle}

MDA-MB-231 stem cells were cultured for 5 days, the cell density was adjusted to $1 \times 10^{5} \mathrm{cells} / \mathrm{mL}$ to prepare a single cell suspension to seed in a 6 -well plate, at a $37^{\circ} \mathrm{C}, 5 \% \mathrm{CO}^{2}$ incubator for $24 \mathrm{~h}$, then add the different drugs $(0$, tetrandrine $(1.5 \mu \mathrm{g} / \mathrm{ml})$, arsenic trioxide $(2.5 \mu \mathrm{g} / \mathrm{ml})$ and tetrandrine combined with arsenic trioxide), to culture for $48 \mathrm{~h}$. After the end of the culture, collect the culture solution and cells in each well. Follow the steps below to detect cell apoptosis using flow cytometry. PBS wash once, discard the supernatant, add $1 \times$ Binding Buffer $100 \mu \mathrm{L}$ to resuspend the cells; add $5 \mu \mathrm{L}$ FITC Annexin V and $5 \mu \mathrm{L} \mathrm{PI}$ to each tube, protect from light, and incubate for $15 \mathrm{~min}$ at room temperature. $200 \mu \mathrm{L}$ of $1 \times$ Binding Buffer was added to each tube. The cell apoptosis was detected by flow cytometry within 1 hour. Then, follow the steps below to detect cell cycle using flow cytometry as well. The supernatant was discarded after washing with PBS, $500 \mu \mathrm{L}$ of pre-cooled $70 \%$ ethanol was added, and placed in a refrigerator at $4{ }^{\circ} \mathrm{C}$ overnight; PBS washed once and $200 \mu \mathrm{L}$ of RNase A-PI was added to each tube protected from light and incubated for 30 minutes at room temperature, the cell cycle was measured by a flow cytometer within 1 hour.

\section{- CCK-8 assay}

The MDA-MB-231 stem cells cultured for 5 days in the second generation were adjusted to a cell density of $8 \times 10^{4}$ cells $/ \mathrm{mL}$ to prepare a single cell suspension; $100 \mu \mathrm{L}$ of single cell suspension was added to each well. After routine incubation for 24 hours at $37^{\circ} \mathrm{C}$ in a $5 \% \mathrm{CO}_{2}$ incubator, the drug-containing culture solutions were separately added with tetrandrine $(0,0.375,0.75,1.5,2,3,6 \mu \mathrm{g} / \mathrm{ml})$ and arsenic trioxide $(0$, $0.625,1.25,2.5,5,10 \mu \mathrm{g} / \mathrm{ml})$. Then, $10 \mu \mathrm{L}$ of CCK-8 solution was added to each well for 4 hours, and the absorbance OD value at a wavelength of $450 \mathrm{~nm}$ was measured with a microplate reader. The cell inhibition rate was calculated using the OD value, and the experiment was repeated three times or more to calculate the cell inhibition rate. The formula is as follows: Cell inhibition rate $(\%)=(1$-average OD value of the experimental group / average OD value of the control group) $\times 100 \%$

\section{- Transwell invasion assay}

Add the diluted Matrigel gel (1:3) to the bottom of the Transwell chamber at $50 \mu \mathrm{l} /$ well, gently shake the 24-well plate to distribute the added liquid evenly and place it in a $37^{\circ} \mathrm{C}$ incubator to gel it into a solid. After two hours, take out, carefully aspirate the liquid culture solution in the small chamber, and air dry for 
use. MDA-MB-231 cells in logarithmic growth phase and stem cells cultured for 5 days were adjusted to a cell density of $1 \times 10^{6} \mathrm{cells} / \mathrm{ml}$. The cells were added to the upper chamber, $150 \mu \mathrm{L}$ of cell suspension per well, and $600 \mu \mathrm{L}$ of serum-containing medium was added to the lower chamber at $37^{\circ} \mathrm{C}$ for 48 hours. Gently wipe off the unmigrated cells and Matrigel gel in the upper chamber, dry it, add methanol for 10 min, add $10 \mu \mathrm{g} / \mathrm{mL}$ DAPI $100 \mu \mathrm{L}$, protect from light, and incubate for $30 \mathrm{~min}$ at room temperature. The underlying cells were observed under an inverted microscope. Each chamber was photographed and the relative invasion index (V2/V1, V2 refers to the number of transmembrane cells of tumor stem cells, and $\mathrm{V} 1$ refers to the number of transmembrane cells of MDA-MB-231 cells) were counted.

\section{- Western blot analysis}

The MDA-MB-231 stem cells cultured for 5 days were washed with pre-cooled PBS, collected into a centrifuge tube, and add the cell lysate (1 mL of RIPA lysate was added to $10 \mu \mathrm{L}$ of PMSF). Measure the cell protein concentration with BCA protein concentration kit, prepare 10\% separation gel, $5 \%$ concentrated gel, electrophoresis, PVDF transfer, and $5 \%$ skim milk for 1 hour. The first antibody was diluted 1:500, overnight at $4^{\circ} \mathrm{C}$. To wash the membrane three times with TBST. With the secondary antibody 1:3000, incubated for 1 hour and washed three times with TBST. Add ECL chemiluminescence solution and expose it with gel imager.

\section{- RNA isolation, preparation of cDNA and Real time PCR analysis}

RNA isolation. MDA-MB-231 cells and 5 days of stem cells were lysed by adding $1 \mathrm{ml}$ of Trizol (invitrogen), allowed to stand at room temperature for $5 \mathrm{~min}$, collected into a $1.5 \mathrm{~mL}$ EP tube, and then $200 \mu \mathrm{L}$ of chloroform was added, followed by vigorous shaking 15 s immediately. After standing for 5 min, it was placed in a centrifuge at $12000 \mathrm{rpm}$ for $15 \mathrm{~min}$ at $4{ }^{\circ} \mathrm{C}$. Carefully pipe the upper liquid into another new centrifuge tube, add $500 \mu \mathrm{L}$ of isopropanol, let stand for $10 \mathrm{~min}$, centrifuge at $12000 \mathrm{rpm}$ for $10 \mathrm{~min}$ at $4^{\circ} \mathrm{C}$, and discard the supernatant. Rinse once with $75 \%$ ethanol, air dry, dissolve in $50 \mu \mathrm{L} \mathrm{DEPC}$ water.

Reverse transcription cDNA. Take a mixture of template RNA $(2 \mu \mathrm{g})$ and oligo $(\mathrm{dT}) 1 \mu \mathrm{l}$, mix gently, centrifuge for 30 seconds, incubate in a $65^{\circ} \mathrm{C}$ incubator for $5 \mathrm{~min}$ and cool on ice. And then it was mixed 5×Reaction Buffer $4 \mu \mathrm{l}$, RiboLock ${ }^{\mathrm{TM}}$ RNase Inhibitor $1 \mu \mathrm{l}, 10 \mathrm{mM}$ dNTP Mix $2 \mu \mathrm{l}$, with RevertAidTM M-MuLV Reverse Transcriptase $1 \mu$ l. Incubate for $60 \mathrm{~min}$ in a $42^{\circ} \mathrm{C}$ incubator. Next, it was placed at $85^{\circ} \mathrm{C}$ and reacted for $10 \mathrm{~min}$ to inactivate reverse transcriptase, cooled at $4^{\circ} \mathrm{C}$ and stored at $-20^{\circ} \mathrm{C}$ until use.

RT-PCR amplification. Mix cDNA $2 \mu \mathrm{l}$, qPCR mix $10 \mu \mathrm{l}$, primer F $1 \mu \mathrm{l}$, primer R $1 \mu \mathrm{l}$ with RNase-free water $6 \mu \mathrm{l}$. Each sample repeated 3 times. $\beta$-actin is an internal reference. Primer sequence is shown in the table below:

\section{- Statistical Analysis}

All results were expressed as mean \pm standard deviation (SD). One-way ANOVA was performed between multiple groups using SPSS 20.0 software when homogeneity of variance and normality were met. 
Otherwise, Dunnett's T3 and nonparametric tests were conducted between multiple groups. $p<0.05$ was considered statistically difference. Drawing with GraphPad Prism 5 software.

\section{Results}

3.1 Enrichment and differentiation of breast cancer cell MDA-MB-231 stem cells

MDA-MB-231 stem cells were enriched by serum-free medium, and the growth of the cells was observed at different time points. Under serum-free medium, MDA-MB-231 stem cells grew in suspension. After $24 \mathrm{~h}$ enrichment, MDA-MB-231 stem cells began to aggregate. As the culture time prolonged, the number of tumor stem cells became more and more and the bigger the volume (Fig1(a)-1(d)). Serum-containing medium was added, and after 24 hours, it was showed a small amount of adherence appeared in the cells. After 72 hours, the adherent cells were gradually increased and began to fuse with the surrounding cells (Fig1(e)-1(h)). There was no statistically difference in morphology between adherent stem cells and MDA-MB-231 cells (Fig 2(i)-2(j)). The results of growth curve showed that suspension cultured MDA-MB231 stem cells were transferred to serum-containing medium and began to differentiate and proliferate on the 1st day, enter to the logarithmic growth period on the 3rd day, and to the platform period on the 7th day (Fig 2(k)).

3.2 Expression of $\mathrm{CD} 44^{+} / \mathrm{CD} 24^{-}$, Oct4mRNA and Sox $2 \mathrm{mRNA}$ and invasive ability in MDA-MB-231 cells and MDA-MB-231 stem cells

Flow cytometry results showed that the ratio of $\mathrm{CD} 44^{+} / \mathrm{CD} 24^{-}$in the MDA-MB-231 cell line was $89.3 \%$, while in the serum-free enriched MDA-MB-231 stem cells was $95.0 \%$ (Fig 3(a)-3(d)). The expression of Oct4 and Sox2mRNA in MDA-MB-231 cells and MDA-MB-231 stem cells was detected by real-time fluorescent quantitative PCR. The results showed that the expression of Oct4 and Sox $2 m R N A$ increased after enrichment in serum-free medium, but the difference is not statistically significant ( $p>0.05$ ) (Fig $3(e)$ ). The Transwell assay results showed that the number of transmembrane cells of tumor stem cells was $758.11 \pm 49.67$, and the number of transmembrane cells of MDA-MB-231 cells was $273.33 \pm 58.41$. The number of MDA-MB-231 stem cell transmembrane cells was significantly higher than that of MDAMB-231 cells $(p<0.01)$ (Fig 3(f)-(h)). MDA-MB-231 stem cell relative invasion index V2/V1 was 2.88 \pm 0.79.

3.5 Effects of tetrandrine and arsenic trioxide on proliferation inhibition of MDA-MB-231 stem cells

The CCK-8 assay results showed that the proliferation of MDA-MB-231 stem cells was inhibited by tetrandrine $(0.375,0.75,1.5,3.0,6.0 \mu \mathrm{g} / \mathrm{mL})$ (Fig $4(\mathrm{a}))$ and arsenic trioxide $(0.625,1.25,2.5,5.0$, $10.0 \mu \mathrm{g} / \mathrm{mL}$ ) (Fig 4(b)). The inhibition effect had taken on time and dose dependence. 
In trypan blue staining, live cells are not stained blue, and dead cells are dyed light blue. In the control group, MDA-MB-231 stem cells grew in a round shape, and some cells aggregated into a cluster. The number of normal stem cells was large, and the blue-stained cells were rarely seen after trypan blue staining. Compared with the control group, intervention with tetrandrine $(1.5 \mu \mathrm{g} / \mathrm{ml})$ and arsenic trioxide $(2.5 \mu \mathrm{g} / \mathrm{ml})$ or combined, the blue cells increased, cell volume shrank, cell debris increased in culture medium, and a large number of cell collapses and died (Fig 5(a)-(d)).

3.7 Effects of arsenic trioxide and tetrandrine on cell apoptosis and cell cycle distribution of MDA-MB-231 stem cells

The results of flow cytometry showed that the effects of tetrandrine and arsenic trioxide on the cell apoptosis and cell cycle of MDA-MB-231 stem cells. The results showed that arsenic trioxide group and the combination of tetrandrine and arsenic trioxide group could significantly promote the apoptosis of MDA-MB-231 stem cells $(p<0.01)$. There was no statistically difference between arsenic trioxide with the combined group to treat BCSCs ( $>>0.05$ ) (Fig 6 (a)-(d) and Table2). Besides, compared with the control group, the percentage of G0/G1 phase cells in the cell cycle was significantly increased $(p<0.05, p<0.01)$ and the $\mathrm{G} 2 / \mathrm{M}$ phase was decreased $(\mathrm{p}<0.01)$ in the combination group and tetrandrine group, which could lead to the cell DNA synthesis and cell proliferation reduced. Compared with the control group, there was no statistically difference in the arsenic trioxide group ( $p>0.05)$ (Fig $6(e)-(h)$ and Table3).

3.9 Effects of arsenic trioxide and tetrandrine on the expression of GLI1, SMO, PTCH, PTEN and Notch1 proteins in MDA-MB-231 stem cells

Western blot analysis results (Fig 7(a)-(f)) showed that compared with the control group, arsenic trioxide, tetrandrine and the combined group could significantly reduce the expression of GLI1 and SMO and increase the expression of PTEN protein $(\mathrm{P}<0.05)$. The expression of PTCH and Notch1 protein had a decreasing trend than the control group, but there was no statistically difference $(P>0.05)$.

\section{Discussion}

Using the serum-free suspension culture, we made MDA-MB-231 stem cells enriched. The ration of the serum-free enriched MDA-MB-231 stem cells was $95.0 \%$. The expression of Oct4 and Sox2mRNA increased and the invasion ability was stronger than the MDA-MB-231 cell. Further, it's revealed that tetrandrine, arsenic trioxide, tetrandrine and the combination could inhibit breast cancer stem cell proliferation, block stem cell cycle, induce stem cell apoptosis and necrosis, and the mechanism may be related to decreasing the expression of GLI1 protein and SMO protein and increasing the expression of PTEN protein. 
In 2003, Al-Hajj et al. ${ }^{[23]}$ firstly isolated a group of cells with $\mathrm{CD} 44^{+} / \mathrm{CD} 24^{-/ / \mathrm{low}} / \mathrm{ESA}^{+} / \mathrm{Lin}^{-}$phenotype from breast cancer patients and proved that compared with other cells, the tumorigenicity of the cells with $\mathrm{CD}_{4} 4^{+} / \mathrm{CD} 24^{-/ l o w} / \mathrm{ESA}^{+} / \mathrm{Lin}^{-}$phenotype is increased by 50 times, and with the potential of multidirectional differentiation and self-renewal, confirming the existence of BCSCs. It is believed that CSC could form microspheres in serum-free medium. $\mathrm{CD} 44^{+} \mathrm{CD} 24^{-}$cells could sort from these spheres and possess higher ability of sphere formation ${ }^{[24]}$. In this experiment, we enriched the stem spheres with serum-free medium containing DMEM/F12, supplemented with bFGF, EGF and B27. Fillmore et al. ${ }^{[25]}$ found that in the breast cancer cell lines MDA-MB-231, SUM159, SUM315, the proportion of CD $44^{+}$CD $24^{-}$ phenotype was above $90 \%$. In our study, it was found that the ratio of $\mathrm{CD} 44^{+} \mathrm{CD} 24^{-}$was found highly expressed in MDA-MB-231 cells (89.3\%) and stem cells (95\%), which was consistent with previous findings.

Embryonic stem cells transcription factors such as octamer-binding transcription factor 4 (Oct4) and sex determining region Y-box 2 (Sox2) are thought to be involved in the regulatory of stem cells and contribute to tumorigenesis and progression of human breast cancer ${ }^{[26]}$. While other studies reported that overexpression of OCT4 could inhibit the metastasis of breast cancer cells ${ }^{[27]}$. Besides, Sox2 is considered to be one of the important stem cell transcription factors. Al-Joudi et al. ${ }^{[28]}$ retrospectively analyzed 382 cases of invasive breast cancer. The expression of Sox 2 was detected by immunohistochemistry and the positive rate was $68.1 \%$. Mimeault et al. ${ }^{[29]}$ found that Sox2, a transcription factor with differentiation potential, affects epigenetic recombination and stem cell characteristics during tumor formation and progression, and is expected to be an important molecular marker for predicting the risk of tumor metastasis and disease recurrence. In this study, real-time quantitative PCR was used to detect the expression of Oct4 and Sox2 genes in MDA-MB-231 cells and MDA-MB-231 stem cells. We found that the expression of Oct4 and Sox2mRNA of BCSCs increased, but the difference is not statistically significant ( $p>0.05)$. The reason may be that the MDA-MB-231 cell and its serum-free enriched MDA-MB-231 stem cells have a relatively high proportion of CD $44^{+} \mathrm{CD} 24^{-}$ phenotype cells, and the content is relatively high, so there was no statistically difference in the expression of Oct4 and Sox2mRNA. Besides, our results showed that human triple negative breast cancer MDA-MB-231 cells had certain invasive ability, which might due to the high proportion of CD $44^{+} C D 24$ phenotype cells and expression of Oct4 and Sox2mRNA. However, the invasiveness ability of BCSCs was significantly higher than that of MDA-MB-231 cells $(p<0.01)$.

Our previous study found that tetrandrine could induce autophagy in triple negative breast cancer MDAMB-231 cells by inhibiting PI3K/AKT/mTOR signaling pathway ${ }^{[30]}$. Besides, $\mathrm{As}_{2} \mathrm{O}_{3}$ combined with tetrandrine inhibited proliferation of breast cancer MDA-MB-231 cells, its mechanism might relate to the cell G2/M phase arrest, bcl-2 protein level decreased to promote apoptosis, GSK3 $\beta$ protein and PARP protein levels up-regulated ${ }^{[31]}$. Chen et al. ${ }^{[32]}$ also indicated that tetrandrine could enhance the anti-cancer effect induced by $\mathrm{As}_{2} \mathrm{O}_{3}$. As to the anti-cancer effect of $\mathrm{As}_{2} \mathrm{O}_{3}$ and tetrandrine on MDA-MB-231 cell, we further study their function on BCSCs and explore the mechanism of anti-breast cancer metastasis. In 
this study, after isolation and identification of MDA-MB-231 stem cell characteristics, we further study the effect of tetrandrine and arsenic trioxide on BCSCs. We found that different concentrations of tetrandrine, arsenic trioxide, and two drugs combined could significantly inhibit the proliferation of BCSCs in a timedose dependent manner. In addition, tetrandrine $(1.5 \mu \mathrm{g} / \mathrm{mL})$ and arsenic trioxide $(2.5 \mu \mathrm{g} / \mathrm{mL})$ for $48 \mathrm{~h}$ had a high synergy degree on BCSCs. In the morphology of BCSCs, compared with the control group, the combination of Tet and ATO for $48 \mathrm{~h}$ had taken on more cell death and smaller cell size of BCSCs. In addition, the effects of arsenic trioxide and tetrandrine on the apoptosis and cycle distribution of MDAMB-231 stem cells were detected by flow cytometry. The results show that the combination of tetrandrine and arsenic trioxide could induce the apoptosis of MDA-MB-231 stem cells, and the ability of combined group is better than that of tetrandrine alone. For the cell cycle, tetrandrine alone or in combination with arsenic trioxide could increase the G0/G1 phase, arrest the G2/M phase to reduce DNA synthesis and cell proliferation, while arsenic trioxide alone was not.

Abnormalities and dysregulation in the signaling pathways such as Notch, Hedgehog, PTEN/PI3K/Akt, may lead to malignant transformation, which are important ways to participate in cancer stem cell formation, transformation and to ensure tumor viability ${ }^{[3]}$. The Hedgehog signal transduction pathway mainly includes Hedgehog $(\mathrm{HH})$ ligands and their receptors Patched (PTCH) and Smoothened (SMO) ${ }^{[34]}$. In ER-positive breast cancer cells, $\mathrm{E}_{2}$ directly binds to the promoter region of the GLI1 gene, activates Hh signaling through non-canonical pathways, increases GLI1 expression, promotes GLI1 target gene activity, and increases CSC self-renewal ${ }^{[35]}$. Besides, emerging preclinical data also implicated $\mathrm{Hh}$ signaling in TNBC pathogenesis. The high expression level of GLI1, the key downstream effector of the Hedgehog signaling pathway, is associated with triple-negative breast cancer stem cells and TNBC patients' unfavorable overall survival rate ${ }^{[36]}$. Activation of the PI3K/AKT pathway is essential for maintaining the dryness and chemoresistance of breast CSCs. PTEN is a tumor suppressor in human breast cancer, which can negatively regulate the role of PI3K/AKT signaling pathway in tumor suppressor genes ${ }^{[37,38]}$. In the present study, compared with the control group, arsenic trioxide, tetrandrine and the combination could significantly reduce the expression of GLI1 and SMO and increase the expression of PTEN protein $(P<0.05)$, which might be the anti-BCSCs mechanism of arsenic trioxide and tetrandrine.

However, there are some limits should be noted in the present study. We provided a preliminary experimental basis for the study of the mechanism of tetrandrine in combination with arsenic trioxide in the treatment of triple-negative breast cancer stem cells, but no gene knockout was performed, and no pathway inhibitors were used for further validation. Therefore, although this study provides an effective drug for the treatment of triple-negative breast cancer stem cells, it is necessary to further study the mechanism of tetrandrine combined with arsenic trioxide in the treatment of triple-negative breast cancer stem cells to better serve the clinic.

\section{Conclusions}


We have proposed a new approach to treat triple-negative breast cancer and metastasis targeting breast cancer stem cells (BCSCs). The high expression of CD44 ${ }^{+}$CD24; Oct4, Sox2 and high invasive ability were characteristics of MDA-MB-231 stem cells. In this study, breast cancer stem cells were enriched by serum-free growth factor-containing medium and their characteristics have been verified. Intervention with tetrandrine and arsenic trioxide on BCSCs induced the apoptosis, increased the G0/G1 phase cells and reduced the G2/M phase cells, which leading to inhibition of the DNA synthesis and cell proliferation. The mechanism might be due to the expression of GLI and SMO were decreased and PTEN expression was increased. This study provided experimental basis for the clinical treatment of anti-triple-negative breast cancer metastasis targeting BCSCs by arsenic trioxide combined with tetrandrine.

\section{Declarations}

\section{Ethics approval and consent to participate}

Not applicable.

\section{Consent for publication}

Not applicable

\section{Availability of data and materials}

The datasets used and/or analysed during the current study are available from the corresponding author on reasonable request.

\section{Competing interests}

The authors declare that they have no competing interests

\section{Funding}

This study was funded by grants from National Natural Science Foundation of China (NSFC 81774319), (NSFC 81560775), and Beijing Natural Science Foundation Project (7182098).

\section{Authors' contributions}

YG was a major contributor in writing the manuscript. XP contributed to the design of the study and analytic strategy. YF and RW performed the experiment and analyzed the data. All authors read and approved the final manuscript.

\section{Acknowledgements}

We would like to thank the National Natural Science Foundation of China and the Beijing Natural Science Foundation for funding and thank our lab stuff for their cooperation. 


\section{References}

1. Upreti M, Jyoti A, Johnson SE, Swindell EP, Napier D, Sethi P, Chan R, Feddock JM, Weiss HL, O'Halloran TV et al. Radiation-enhanced therapeutic targeting of galectin-1 enriched malignant stroma in triple negative breast cancer. Oncotarget 2016, 7(27):41559-41574.

2. Dey P, Rathod M, De A. Targeting stem cells in the realm of drug-resistant breast cancer. Breast Cancer (Dove Med Press) 2019, 11:115-135.

3. Chang JC, Li X, Wong H, Creighton C, S.G.Hilsenbeck, C.K.OsborneJ.M.Rosen, M.T.Lewis. Therapeutic resistance and tumor-initiation: Molecular pathways involved in breast cancer stem cell self-renewal. Journal of Clinical Oncology 2007, 25:528-540.

4. Nami $B$, Donmez $H$, Kocak $N$. Tunicamycin-induced endoplasmic reticulum stress reduces in vitro subpopulation and invasion of CD44+/CD24- phenotype breast cancer stem cells. Experimental and Toxicologic Pathology 2016, 68(7):419-426.

5. Uchiumi K, Tsuboi K, Sato N, Uchiumi K, Tsuboi K, Sato N, Ito T, Hirakawa H, Niwa T, Yamaguchi Y et al. Cancer stem-like properties of hormonal therapy-resistant breast cancer cells. Breast Cancer 2019:doi: 10.1007/s12282-12018-00944-12281.

6. Palomeras S, Ruiz-Martínez S, Puig T. Targeting Breast Cancer Stem Cells to Overcome Treatment Resistance. Molecules 2018, 23(9):2193.

7. Guo M, Wang B, Liu S, Wang W, Gao C, Hu S, Fan S, Hai X, Zhou J. Time course of arsenic species in red blood cells of acute promyelocytic leukemia (APL) patients treated with single agent arsenic trioxide. Expert Rev Clin Pharmacol 2019, 12(4):371-378.

8. Huang W, Zeng YC. A candidate for lung cancer treatment: arsenic trioxide. Clinical and Translational Oncology 2019:1-12.

9. Stevens JJ, Graham B, Dugo E, Berhaneselassie-Sumner B, Ndebele K, Tchounwou PB. Arsenic Trioxide Induces Apoptosis via Specific Signaling Pathways in HT-29 Colon Cancer Cells. J Cancer Sci Ther 2017, 9(1):298-306.

10. Wang L, Wang R, Fan L, Liang WT, Liang K, Xu YX, Peng GZ, FaYe Q. Arsenic trioxide is an immune adjuvant in liver cancer treatment. Mol Immunol 2017, 81:118-126.

11. Abudoureyimu A, Muhemaitibake A. Arsenic trioxide regulates gastric cancer cell apoptosis by mediating cAMP. Eur Rev Med Pharmacol Sci 2017, 21(3):612-617.

12. Gao JK, Wang LX, Long B, Ye X, Su JN, Yin XY, Zhou XX, Wang ZW. Arsenic Trioxide Inhibits Cell Growth and Invasion via Down- Regulation of Skp2 in Pancreatic Cancer Cells. Asian Pac J Cancer Prev 2015, 16(9):3805-3810.

13. Luo D, Zhang XY, Du R, Gao WJ, Luo N, Zhao ST, Li Y, Chen R, Wang H, Bao YH et al. Low dosage of arsenic trioxide (As203) inhibits angiogenesis in epithelial ovarian cancer without cell apoptosis. $J$ Biol Inorg Chem 2018 23(6):939-947.

14. Laka K, Makgoo L, Mbita Z. Survivin Splice Variants in Arsenic Trioxide (As『OX)-Induced Deactivation of PI3K and MAPK Cell Signalling Pathways in MCF-7 Cells. Genes (Basel) 2019, 10(1):1-21. 
15. Moghaddaskho F, Eyvani H, Ghadami M, Tavakkoly-Bazzaz J, Alimoghaddam K, Ghavamzadeh A, Ghaffari SH. Demethylation and alterations in the expression level of the cell cycle-related genes as possible mechanisms in arsenic trioxide-induced cell cycle arrest in human breast cancer cells. Tumour Biol 2017, 39(2):1-16.

16. Wang Y, Wang L, Yin C, An BZ, Hao YK, Wei T, Li L, Song GC. Arsenic trioxide inhibits breast cancer cell growth via microRNA-328/hERG pathway in MCF-7 cells. Mol Med Rep 2015, 12(1):1233-1238.

17. Li Y, Jiang F, Liu Q, Shen J, Wang X, Li Z, Zhang J, Lu X. Inhibition of the cancer stem cells-like properties by arsenic trioxide, involved in the attenuation of endogenous transforming growth factor beta signal. Toxicol Sci 2015, 143(1):156-164.

18. Shishodia G, Koul S, Dong Q, Koul HK. Tetrandrine (TET) Induces Death Receptors Apo Trail R1 (DR4) and Apo Trail R2 (DR5) and Sensitizes Prostate Cancer Cells to TRAIL-Induced Apoptosis. Mol Cancer Ther 2018, 17(6):1217-1228.

19. Chen Z, Zhao L, Zhao F, Yang G, Wang JJ. Tetrandrine suppresses lung cancer growth and induces apoptosis, potentially via the VEGF/HIF-1a/ICAM-1 signaling pathway. Oncol Lett 2018, 15(5):74337437.

20. Dang Y, Xu Y, Wu W, Li W, Sun Y, Yang J, Zhu Y, Zhang C. Tetrandrine suppresses lipopolysaccharideinduced microglial activation by inhibiting NF-KB and ERK signaling pathways in BV2 cells. PLOS One 2014, 9(8):e102522.

21. Yuan B, Yao MJ, Wang X, Sato A, Okazaki A, Komuro H, Hayashi H, Toyoda H, Pei XH, Hu XM et al. Antitumor activity of arsenite in combination with tetrandrine against human breast cancer cell line MDA-MB-231 in vitro and in vivo. Cancer Cell Int 2018, 18:113.

22. Dandawate PR, Subramaniam D, Jensen RA, Anant $S$. Targeting cancer stem cells and signaling pathways by phytochemicals: Novel approach for breast cancer therapy. Semin Cancer Bio/ 2016, 40(41):192-208.

23. Al-Hajj M, Wicha MS, Benito-Hernandez A, Morrison SJ, Clarke MF. Prospective identification of tumorigenic breast cancer cells. Proc Natl Acad Sci U S A 2003, 100(7):3983-3988.

24. Ge G, Zhou C, Ren Y, Tang XJ, Wang K, Zhang W, Niu LG, Zhou YH, Yan Y, He JJ. Enhanced SLC34A2 in breast cancer stem cell-like cells induces chemotherapeutic resistance to doxorubicin via SLC34A2-Bmi1-ABCC5 signaling. Tumour Biol 2016, 37(4):5049-5062.

25. Fillmore $\mathrm{CM}$, Kuperwasser $\mathrm{C}$. Human breast cancer cell lines contain stem-like cells that self-renew, give rise to phenotypically diverse progeny and survive chemotherapy. Breast Cancer Res 2008, 10(2):R25.

26. Gwak JM, Kim M, Kim HJ, Jang MH, Park SY. Expression of embryonal stem cell transcription factors in breast cancer: Oct4 as an indicator for poor clinical outcome and tamoxifen resistance. Oncotarget 2017, 8(22):36305-36318.

27. Saha SK, Jeong Y, Cho S, Cho S-G. Systematic expression alteration analysis of master reprogramming factor OCT4 and its three pseudogenes in human cancer and their prognostic outcomes. Sci Rep 2018, 8(1):14806. 
28. FS A-J, ZA I, J H, J R, Y K, K IA, M A, J Z. Expression of survivin and its clinicopathological correlations in invasive ductal carcinoma of the breast. Singapore Med 2007, 48(7):607-614.

29. Mimeault M, Batra SK. Molecular biomarkers of cancer stem/pro genitor cells associated with progression, metastases and treatment resistance of aggressive cancers. Cancer Epidemiol Biomarkers Prev 2014, 23(2):234-254.

30. Guo Y, Pei X. Tetrandrine-Induced Autophagy in MDA-MB-231 Triple-Negative Breast Cancer Cell through the Inhibition of PI3K/AKT/mTOR Signaling. Evid Based Complement Alternat Med 2019, 2019:7517431.

31. Yu B, Fan Y, Guo Y, Pei X. Inhibitory effect of sodium arsenite combined with tetrandrine on proliferation of breast cancer MDA-MB-231 cells and its mechanism. Journal of Modern Oncology 2019, 27(4):546-551.

32. Chen Y, Li P, Yang S, Tong N, Zhang J, Zhao X. Tetrandrine enhances the anticancer effects of arsenic trioxide in vitro. Int J Clin Pharmacol Ther 2014, 52(5):416-424.

33. FaezehGhasemi, ZiaSarabi P, ShamsadinAthari S, AbdolrezaEsmaeilzadeh. Therapeutics strategies against cancer stem cell in breast cancer. Int J Biochem Cell Biol 2019, 109:76-81.

34. Cochrane CR, Szczepny A, Watkins DN, Cain JE. Hedgehog Signaling in the Maintenance of Cancer Stem Cells. Cancers (Basel) 2015, 7(3):1554-1585.

35. Kurebayashi J, Koike Y, Ohta Y, Saitoh W, Yamashita T, Kanomata N, Moriya T. Anti-cancer stem cell activity of a hedgehog inhibitor GANT61 in estrogen receptor-positive breast cancer cells. Cancer Sci 2017, 108(5):918-930.

36. So JY, Lin JJ, Wahler J, Liby KT, Sporn MB, Suh N. A Synthetic Triterpenoid CDDO-Im Inhibits Tumorsphere Formation by Regulating Stem Cell Signaling Pathways in Triple-Negative Breast Cancer. PLoS One 2014, 8(9):e107616.

37. Cui C, Li S, Wu D. Znhit1 inhibits breast cancer by up-regulating PTEN to deactivate the PI3K/Akt/mTOR pathway. Life Sciences 2019, 224:204-211.

38. Hu Y, Guo R, Wei J, Zhou Y, Ji W, Liu J, Zhi X, Zhang J. Effects of PI3K inhibitor NVP-BKM120 on overcoming drug resistance and eliminating cancer stem cells in human breast cancer cells. Cell Death Dis 2015, 6(12):e2020.

\section{Tables}

Due to technical limitations, the tables have been placed in the supplementary files section.

\section{Figures}



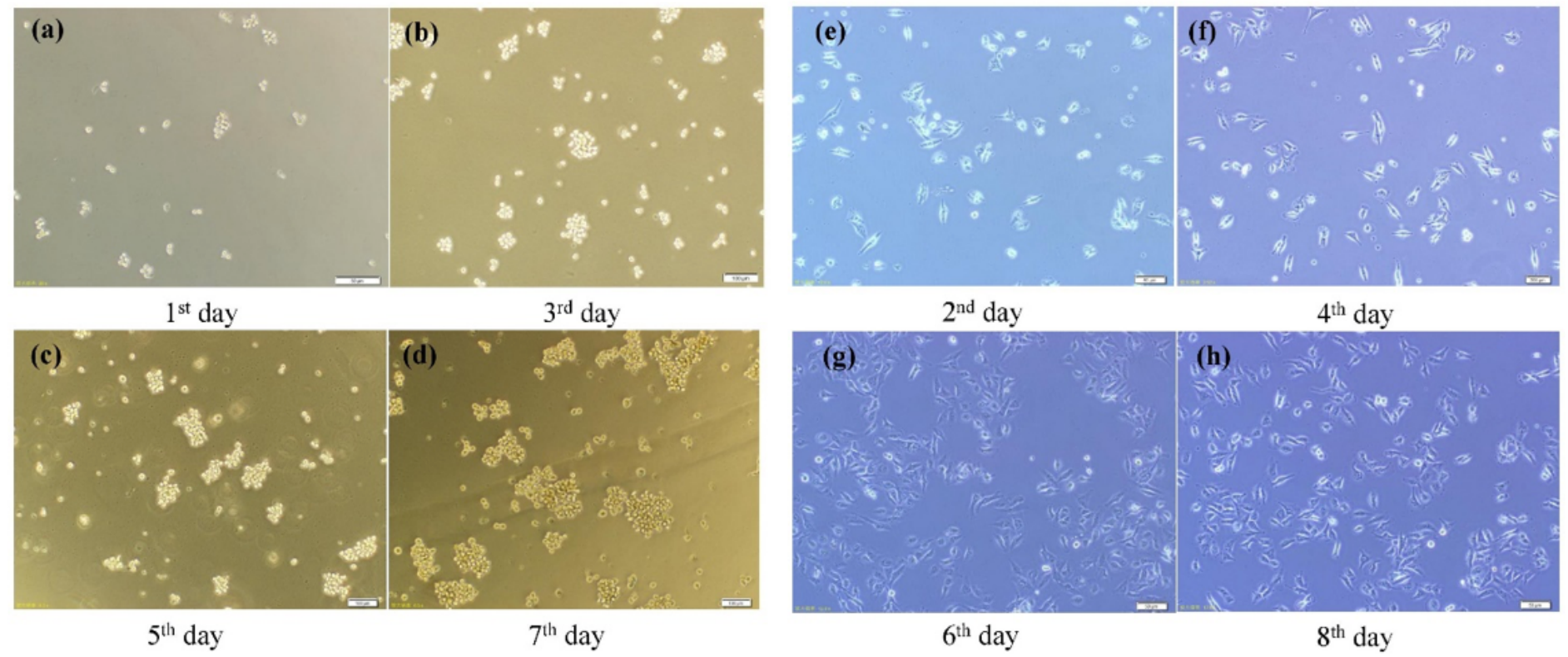

\section{Figure 1}

Microscopic morphology of MDA-MB-231 stem cell microspheres enriched by serum-free medium (a-d) and cultured by serum-containing medium (e-h) (10x).

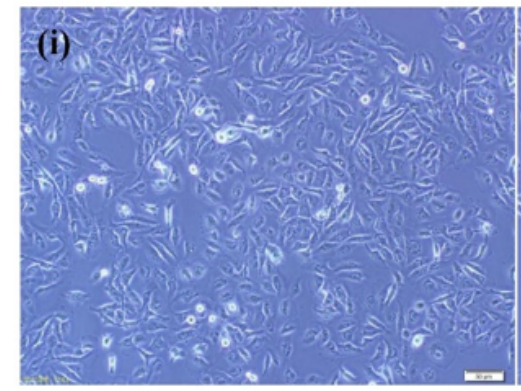

MDA-MB-231 cells

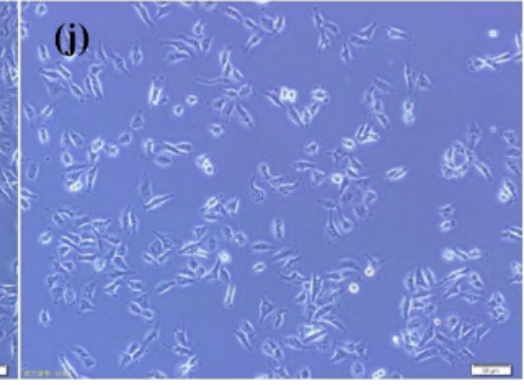

MDA-MB-231 stem cells (k)

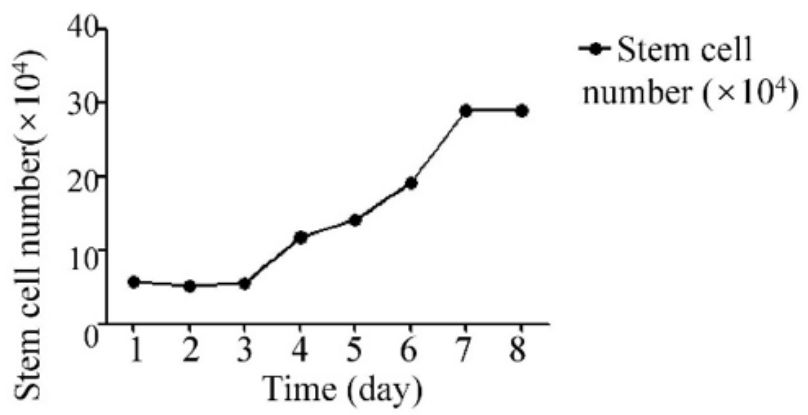

\section{Figure 2}

Morphology comparison of MDA-MB-231 cells and MDA-MB-231 stem cells (i-j, 10x) and the growth curve of MDA-MB-231 stem cells $(k)$ with serum-containing medium. 

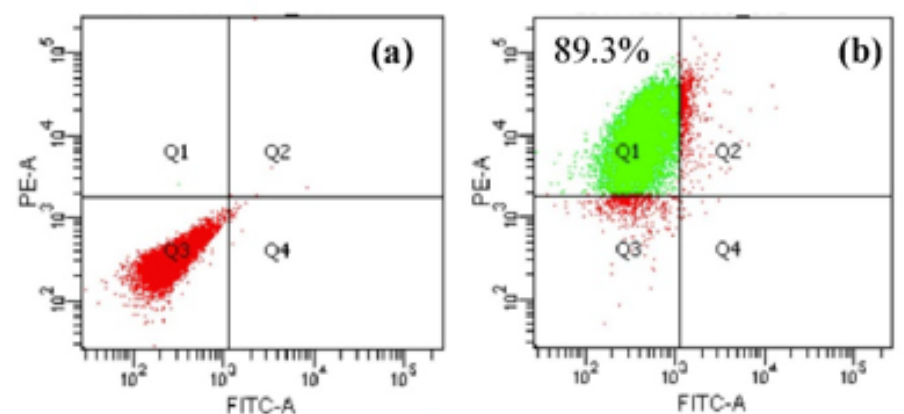

(e)
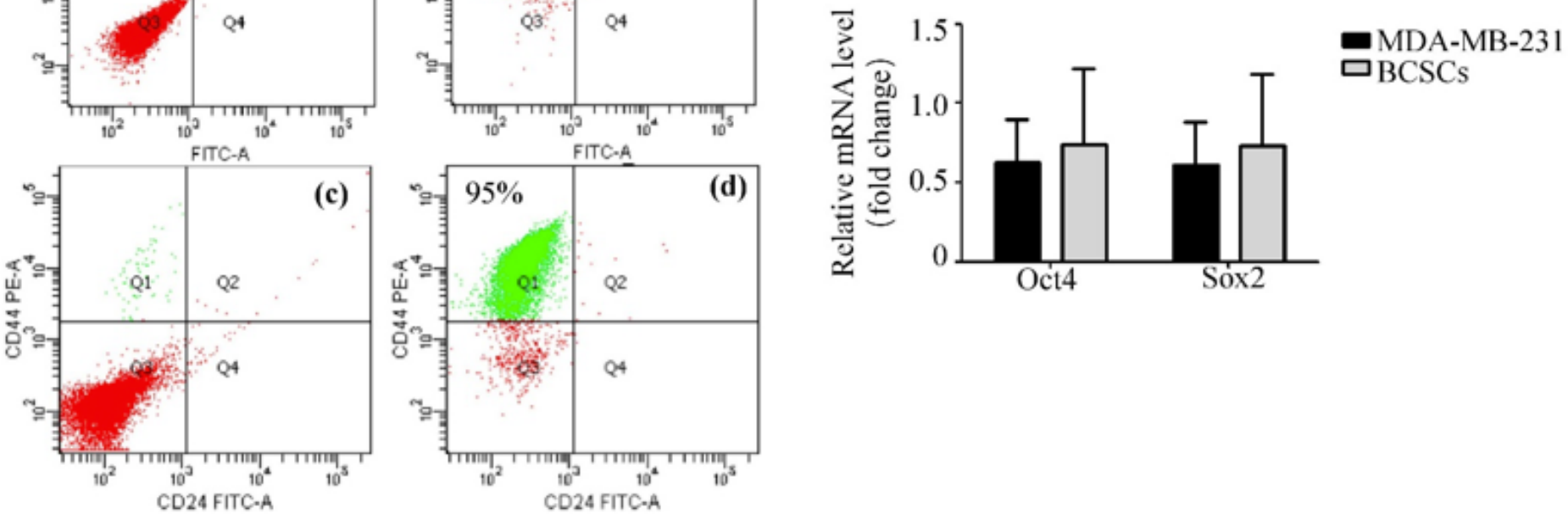

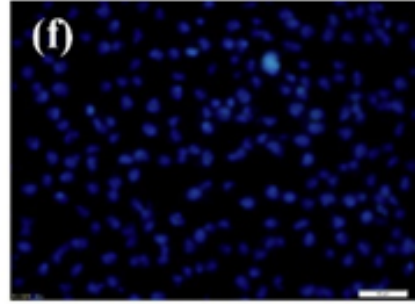

MDA-MB-231

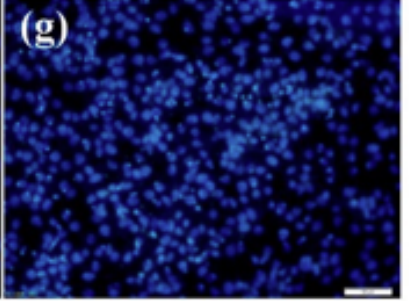

BCSCs

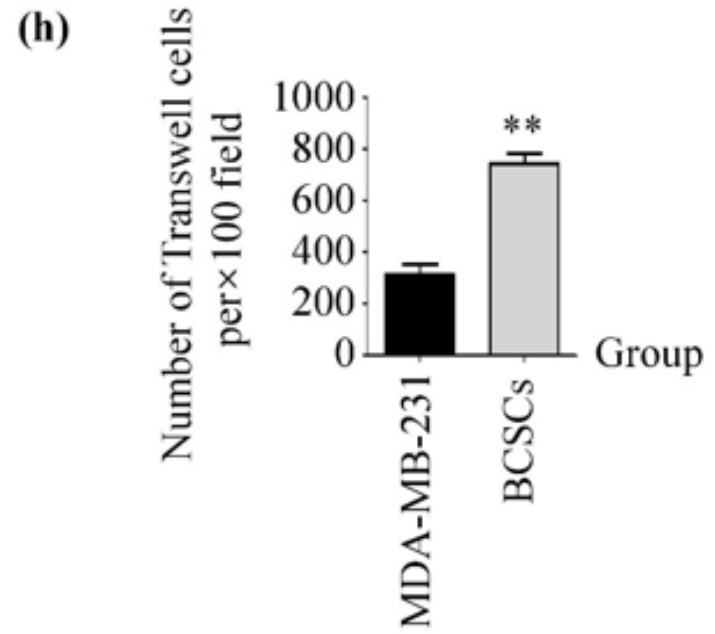

\section{Figure 3}

Stem characteristics measurement of CD44+CD24-proportion by flow cytometry (Fig a-d); Oct4 and Sox2 mRNA expression of BCSCs by rt-PCR (Fig e); Invasion ability by Transwell assay(Fig $\mathrm{f}-\mathrm{g}$ ) and data analysis Fig (h) of MDA-MB-231 cells and BCSCs.

(a)

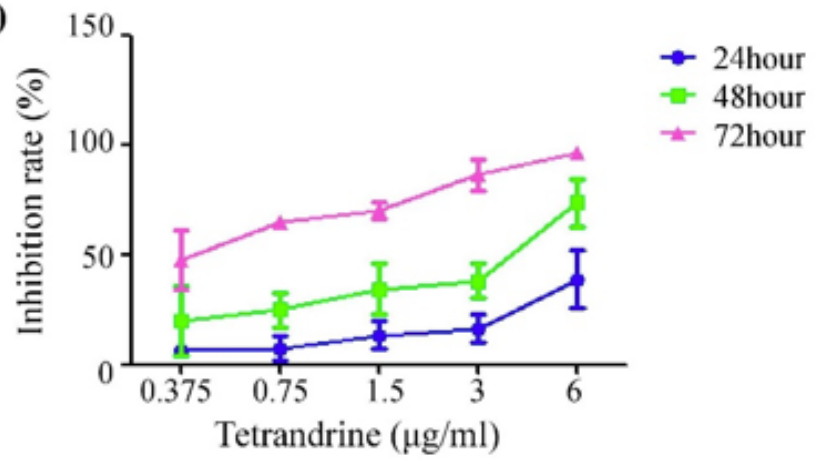

(b)

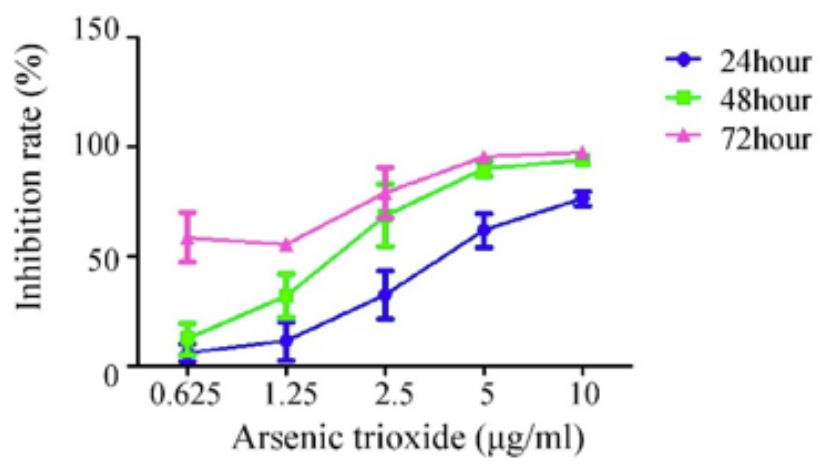


Figure 4

The inhibition rate of Tetrandrine and Arsenic trioxide on BCSCs for 24, 48,72hour. 3.6 Effects of arsenic trioxide and tetrandrine on the morphology of MDA-MB-231 stem cells

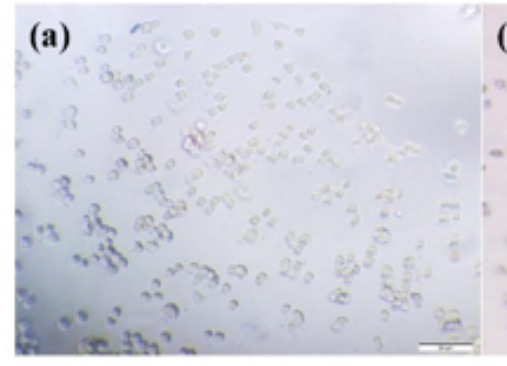

Control (b)

Tet (c)

(d)

\section{Figure 5}

Trypan blue staining to observe the effect of arsenic trioxide combined with tetrandrine on the morphology of MDA-MB-231 stem cells after 48 hours (Fig (a)-(d), magnification 10x, blue cells represent dead cells). 3.7 Effects of arsenic trioxide and tetrandrine on cell apoptosis and cell cycle distribution of MDA-MB-231 stem cells
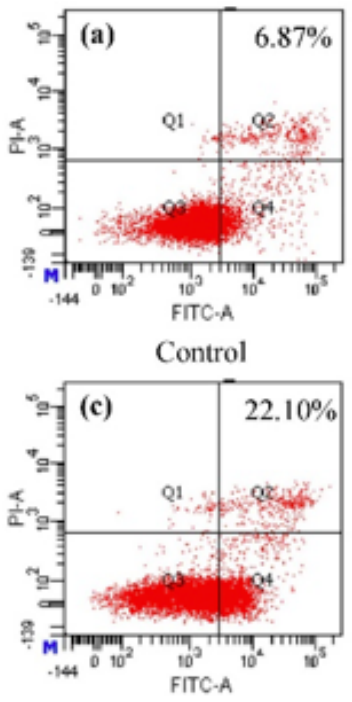

ATO
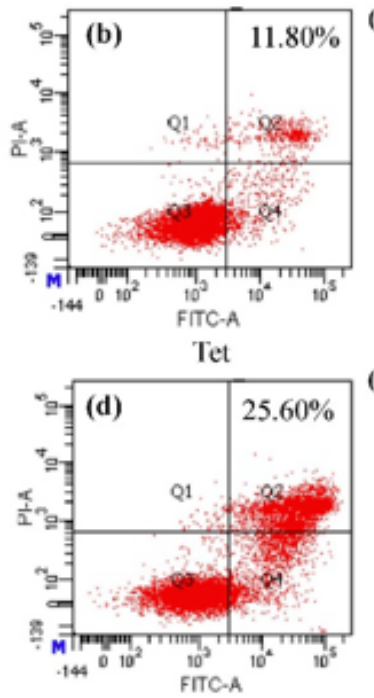

Tet + ATO
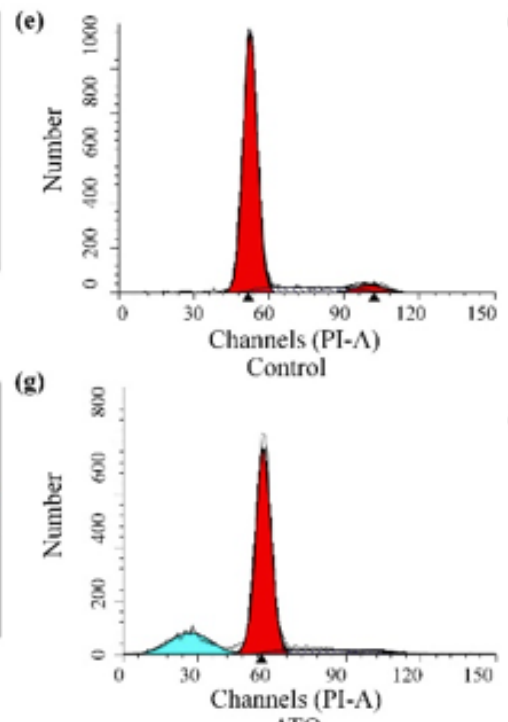

ATO
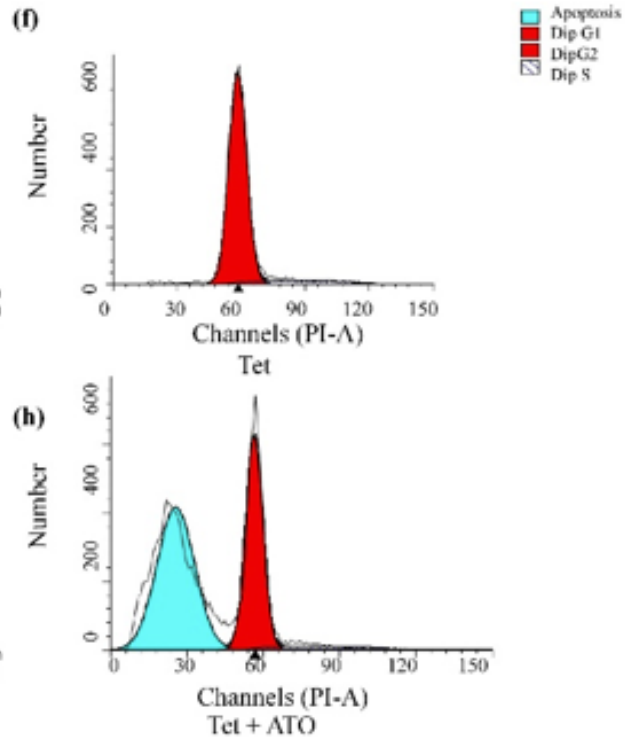

\section{Figure 6}

Effect of arsenic trioxide and tetrandrine on apoptosis percentage (Fig (a)-(d)) and cell cycle percentage (Fig (e)-(h)) of MDA-MB-231 stem cells by flow cytometry. 
(a)

PTEN

GLI1

(b)

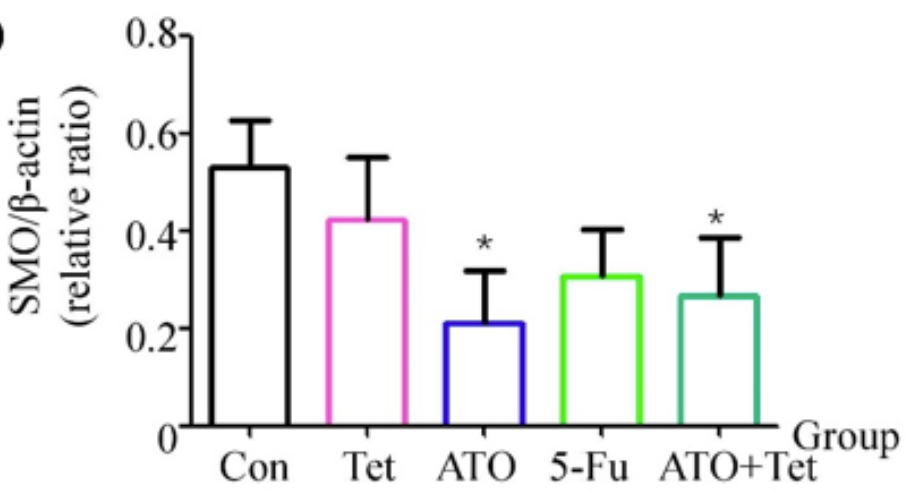

(c)

(d)
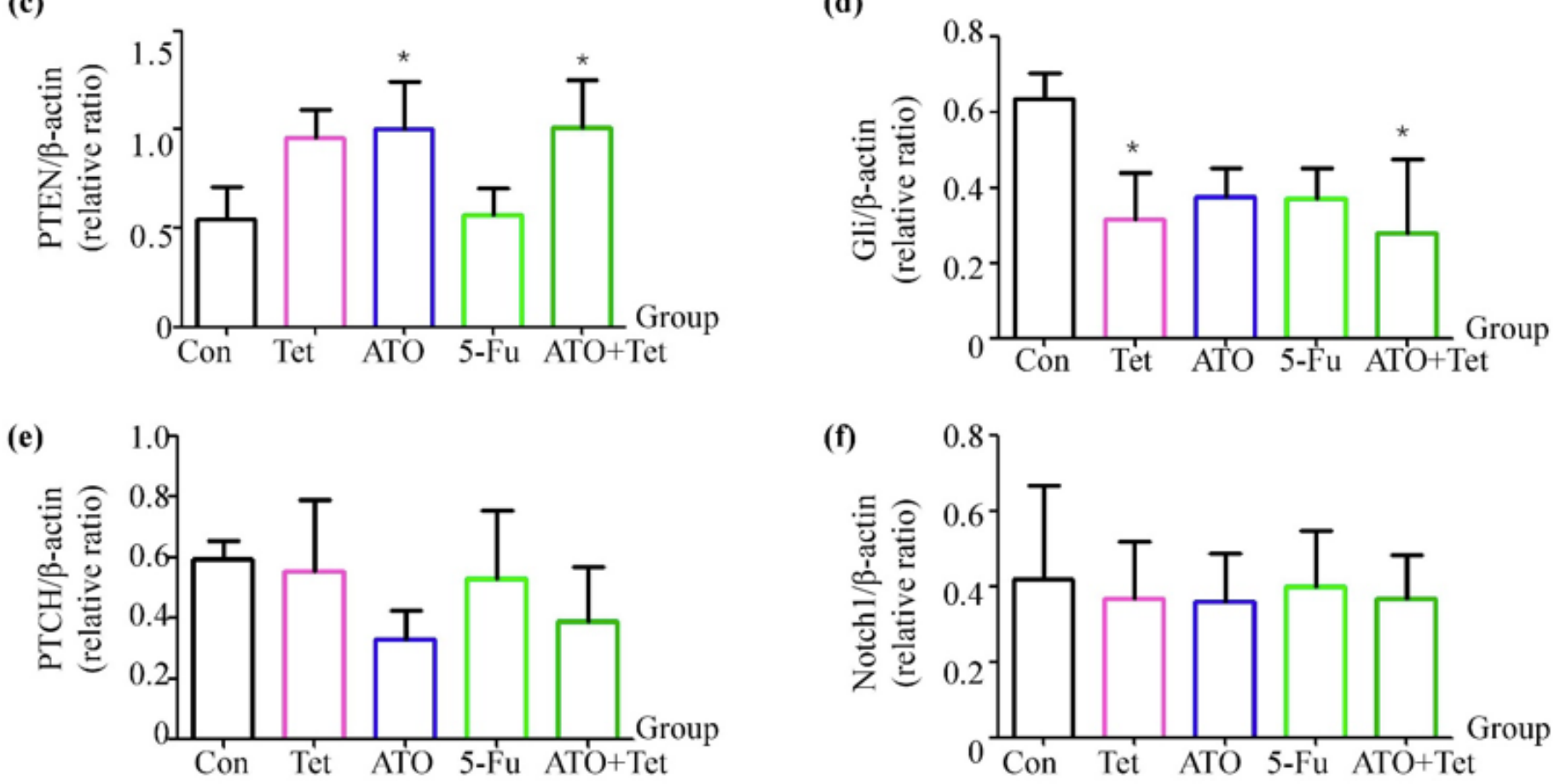

Figure 7

Effect of arsenic trioxide and tetrandrine on apoptosis percentage (Fig (a)-(d)) and cell cycle percentage (Fig (e)-(h)) of MDA-MB-231 stem cells by flow cytometry.

\section{Supplementary Files}

This is a list of supplementary files associated with this preprint. Click to download.

- Table1.png

- Table3.png

- Table2.png 